Supplementary File 1 - General Practice Staff Survey

Study ID:

Today's date $(\mathrm{dd} / \mathrm{mm} / \mathrm{yyyy})$ :

Name of General Practice you work at:

\title{
INFORMATION ABOUT YOU
}

1. Occupation (please tick one)

$\square$ General Practitioner

$\square$ Practice Nurse

2. Please indicate the length of time that you have been working in this practice:
$\square \leq 1$ year
2-5 years
6-10 years
11-14 years
$\square \geq 15$ years

3. Which of the following categories best fits your age? (Please tick only one)
$\square 20$ - 29 years
$50-59$ years
30 - 39 Years
60 - 69 years
$40-49$ Years
$\geq 70$ years

4. What is your gender?

$\square$ Male

$\square$ Female 
5. a) Do you think that the use of MBS billable Chronic Disease Management items undertaken for chronic disease patients in your practice has changed since becoming part of GCIC? (GP Management Plans (721, 732), Team Care Arrangements (723), Multidisciplinary Care Plans (729) and Multidisciplinary Case Conferencing (735758))
$\square$ No
$\square$ Yes - Increased
Yes - Decreased
$\square$ Not sure

b) Please indicate the factors that influenced your response to the previous question (tick more than one if necessary):

$\square$ Increased need for chronic disease management

$\square$ Chronic disease management no longer required

$\square$ Services coordinated by GCIC

$\square$ Increased time pressures

$\square$ Increased patient engagement

$\square$ Decreased patient engagement

$\square$ Increased practice focus on acute rather than chronic conditions

$\square$ Decreased practice focus on acute rather than chronic conditions

$\square$ Other

c) Please comment 
6. Since joining the Integrated Care program, can you rate your communication about patients with Gold Coast Hospital and Health Service (Please tick one answer for each)

\section{Adequate}

Never Rarely Sometimes Mostly Always

...the information I receive gives me an

overview of patient care.

\section{Comprehensive}

...the information I receive gives me a complete

picture of patient's care.

\section{Effective}

...the information enables me to continue care of patients.

Accurate

...the information I receive is correct.

\section{Timely}

...I receive information in time for it to be

useful for patient's next surgery visit.

7. Since joining the Integrated Care program, can you rate your communication about patients with Gold Coast Integrated Care (Please tick one answer for each)

\section{Adequate}

Never Rarely Sometimes Mostly Always

...the information I receive gives me an overview of patient care.

\section{Comprehensive}

...the information I receive gives me a complete picture of patient's care.

\section{Effective}

...the information enables me to continue care of patients.

Accurate

...the information I receive is correct.

\section{Timely}

...I receive information in time for it to be useful for patient's next surgery visit. 
8. Since joining the Integrated Care program, can you rate your communication about patients with other health services (Please tick one answer for each)

Never Rarely Sometimes Mostly Always

\section{Adequate}

...the information I receive gives me an overview of patient care.

\section{Comprehensive}

...the information I receive gives me a complete picture of patient's care.

\section{Effective}

...the information enables me to continue care

of patients.

\section{Accurate}

...the information I receive is correct.

Timely

...I receive information in time for it to be useful for patient's next surgery visit.

\section{Please rate your overall satisfaction with the following:}

\begin{tabular}{|c|c|c|c|}
\hline $\begin{array}{c}\text { Very } \\
\text { dissatisfied }\end{array}$ & $\begin{array}{l}\text { Somewhat } \\
\text { dissatisfied }\end{array}$ & $\begin{array}{c}\text { Neither } \\
\text { satisfied nor } \\
\text { dissatisfied }\end{array}$ & $\begin{array}{c}\text { Somewhat } \\
\text { satisfied }\end{array}$ \\
\hline
\end{tabular}

The Nurse Navigator role

Disease Registers/GCIC

Server

Population Based

Ambulatory Care Clinics

Timeliness (or

responsiveness) of the

GCIC program in assisting

with patient care

Overall GCIC program

a. Please comment on any issues affecting your satisfaction with the aspects mentioned above:

10. In your own words, what do you see as the strengths of the GCIC program? 
11. In your own words, can you identify any limitations of the GCIC program that could impact on your practice?

Thank you for completing this survey.

Please return to your Practice Manager or GCIC Nurse Navigator for collection. 